\title{
AFERIÇÃO TÉRMICA EM ALIMENTOS QUE COMPÕEM REFEIÇÕES PORCIONADAS
}

\section{THERMAL ATTENTION IN FOODS COMPOSING PORTIONED FOODS}

\author{
C. M. G. LIMA', K. A. SANTOS ${ }^{2}$, R. M. D. CARDOZO ${ }^{3}$, F. C. DUARTE ${ }^{3}$, R. A. ROCHA ${ }^{1}$, \\ A. R. G. OLIVEIRA ${ }^{3}$
}

Universidade Federal de Lavras

${ }^{2}$ Universidade Estadual do Sudoeste da Bahia

${ }^{3}$ Instituto Federal do Norte de Minas - Campus Salinas

E-mail: claraifnmg@hotmail.com

\author{
article info \\ Article history: \\ Received 12 May 2017 \\ Accepted 3 August 2017 \\ Available online 20 September 2017
}

\begin{abstract}
PALAVRAS-CHAVE: Toxinfecções; Temperaturas; Alimentos; Refeições. KEYWORDS: Toxinfections; Temperatures; Foods; Meals.
\end{abstract}

\begin{abstract}
RESUMO: Serviços de alimentação constituem os estabelecimentos onde o alimento é manipulado, preparado, armazenado e ou exposto à venda, podendo ou não ser consumido no local. Considerando a diversidade de segmentos de alimentação ofertados no Mercado Municipal de Salinas-MG, além da manipulação com produtos $e$ dinheiro concomitantemente, são recorrentes as contaminações microbianas. As toxinfecções de origem bacteriana são as doenças veiculadas por alimentos que mais se relacionam com os serviços de alimentação. $O$ presente trabalho objetivou avaliar as temperaturas de alimentos que compõem refeições porcionadas as quais são comercializadas em barracas no local supracitado. Diariamente, são servidas em oito barracas produtoras de refeições porcionadas os seguintes alimentos: arroz, feijão, carne e uma guarnição. Utilizou-se termômetro infravermelho digital Smart Sensor modelo AR 360 para efetuar as aferições e ficha de registros. Foram realizadas 480 aferições para cada alimento em um período de 4 meses. Os resultados foram analisados segundo as temperaturas preconizadas pela Resolução RDC $n^{\circ} 216$ de 15 de Setembro de 2004 sendo considerados adequados quando em temperatura superior a $60^{\circ} \mathrm{C}$ para as preparações quentes. Os resultados mostraram que pelo menos $75 \%$ das temperaturas estavam em desacordo com a legislação vigente. Assim, é necessário a vigilância sanitária municipal acompanhar e fiscalizar as barracas. O processo produtivo das refeições precisa ser revisto e monitorado, de forma a garantir melhores temperaturas de armazenamento das preparações, garantido aos consumidores uma alimentação com menor risco higiênico-sanitário e melhor qualidade.
\end{abstract}

\footnotetext{
ABSTRACT: Food services are establishments where food is handled, prepared, stored and/or offered for sale, whether or not it is consumed on the premises. Considering the diversity of food segments offered in the Municipal Market of Salinas-MG, besides the manipulation with products and money concomitantly, microbial contaminations are recurrent. Bacterial toxinfections are the food-borne diseases most closely related to food services. The objective of the present study was to evaluate the temperatures of food that are composed of meals that are sold in tents at the aforementioned location. On a daily basis, the following foods are served in eight stall-producing stalls: rice, beans, meat and a garnish. We used a digital infrared thermometer Smart Sensor model AR 360 to perform the measurements and records tab. There were 480 measurements for each food in a period of 4 months. The results were analyzed according to the temperatures recommended by Resolution RDC $N^{\circ} .216$ of September 15, 2004 and considered suitable when at temperatures above $60^{\circ} \mathrm{C}$ for hot preparations. The results showed that at least $75 \%$ of the temperatures were in disagreement with the current legislation. Thus,
} 


\section{The Journal of Engineering and Exact Sciences - \\ JCEC \\ ISSN: 2527-1075}

it is necessary the municipal health surveillance to monitor and supervise the tents. The production process of meals needs to be reviewed and monitored in order to guarantee better storage temperatures of the preparations, guaranteeing to the consumers a food with lower hygienic-sanitary risk and better quality.

\section{INTRODUÇÃO}

Serviços de alimentação são definidos como aqueles estabelecimentos onde o alimento é manipulado, preparado, armazenado e ou exposto à venda, podendo ou não ser consumido no local (BRASIL, 2004). Nesse contexto, o Mercado Municipal de Salinas, configura-se como um espaço ímpar que oferece serviços de alimentação atrativos. Considerando a diversidade de segmentos de alimentação ofertados no local supracitado, além da manipulação com produtos e dinheiro concomitantemente, são recorrentes as contaminações microbianas.

Existem várias doenças veiculadas por alimentos (DVAs), porém as que mais se relacionam com os serviços de alimentação são as toxinfecções de origem bacteriana. A ocorrência dessas doenças está relacionada com vários fatores, tais como: temperatura, armazenamento, conservação, manipulação, hábitos higiênicos, entre outros. Nesse sentido, o controle das temperaturas constitui um dos métodos mais importantes utilizados no processamento de alimentos com o objetivo de minimizar os efeitos indesejáveis e/ou eliminar os microrganismos patógenos e inativar as enzimas (FELLOWS, 2000).

O trabalho em questão objetivou avaliar as temperaturas de alimentos que compõem refeições porcionadas as quais são comercializadas em barracas no Mercado Municipal de Salinas-MG.

\section{MATERIAL E MÉTODOS}

As aferições das temperaturas foram efetuadas do período do almoço, compreendido entre às $11 \mathrm{~h} 00$ e $12 \mathrm{~h} 00$. Diariamente, são servidas em oito barracas produtoras de refeições porcionadas os seguintes alimentos: arroz, feijão, carne e uma guarnição. Utilizou-se termômetro infravermelho digital Smart Sensor modelo AR 360, com faixa de variação entre $50{ }^{\circ} \mathrm{C}$ a $380{ }^{\circ} \mathrm{C}$, direcionando-o para o centro das preparações por cerca de 2 segundos. As temperaturas aferidas foram visualizadas de forma instantânea na tela de cristal líquido do referido termômetro e anotadas na ficha de registros. Foram realizadas 480 aferições para cada alimento em um período de 4 meses. Os resultados foram analisados segundo as temperaturas preconizadas pela Resolução RDC n 216 de 15 de Setembro de 2004 sendo considerados adequados quando em temperatura superior a $60{ }^{\circ} \mathrm{C}$ para as preparações quentes (AGÊNCIA NACIONAL DE VIGILÂNCIA SANITÁRIA, 2004). A análise estatística dos dados foi realizada no software SAS ${ }^{\circledR}$ University Edition. Para comparação entre as temperaturas dos alimentos e o valor de referência utilizou-se a Análise de Variância (ANOVA), seguida do teste de Dunnet, sendo consideradas significativas as diferenças de $\mathrm{p}<$ 0,05 (FIELD, 2009). 


\section{The Journal of Engineering and Exact Sciences - \\ JCEC \\ ISSN: 2527-1075}

\section{RESULTADOS E DISCUSSÃO}

Os resultados das temperaturas médias para os alimentos quentes em oito barracas estão demonstrados na Tabela 1. Os valores das colunas seguidos pela mesma letra, para cada alimento de forma separada não diferem estatisticamente. Assim, com base nos resultados apresentados $100 \%$ das temperaturas das preparações na barraca 4 encontram-se em desacordo com Resolução RDC n 216 de 15 de Setembro de 2004 (ANVISA, 2004). As demais barracas, possuem $75 \%$ das temperaturas inadequadas de acordo à legislação vigente.

Assim como neste estudo, Rocha e colaboradores (2010) encontraram uma parcela significativa de temperaturas inadequadas em alimentos quentes, relatando o armazenamento incorreto na fase de pós preparo bem como a necessidade de medidas de correção e adequação das temperaturas no processo de distribuição das refeições. Vale ressaltar a importância de treinamentos periódicos em Boas Práticas de Fabricação com os manipuladores de alimentos, além do monitoramento da vigilância sanitária municipal.

O estudo em questão mostra-se relevante uma vez que no Brasil há inúmero casos subnotificados às Secretarias Municipal e Estadual de Saúde e à Fundação Nacional de Saúde de surtos de infecção e intoxicação causados por alimentos, os sintomas desta classe de ocorrência (diarreias, vômitos, febre e incapacitações físicas), não costumam ser associados ao consumo de alimentos pelos afetados nem pelos profissionais de atendimento primário à saúde (BARRETO e COSTA, 2006).

Tabela 1 - Médias das temperaturas dos alimentos quentes

\begin{tabular}{ccccc}
\hline \multicolumn{5}{c}{ Temperaturas das preparações quentes } \\
\hline Barracas & Arroz & Feijão & Guarnição & Carne \\
\hline 1 & $51,40 \mathrm{~d}$ & $52,92 \mathrm{f}$ & $50,25 \mathrm{e}$ & $71,62 \mathrm{~b}$ \\
2 & $56,43 \mathrm{~b}$ & $72,01 \mathrm{a}$ & $54,09 \mathrm{~d}$ & $54,50 \mathrm{~d}$ \\
3 & $41,67 \mathrm{f}$ & $54,86 \mathrm{e}$ & $39,74 \mathrm{~g}$ & $66,60 \mathrm{c}$ \\
4 & $50,58 \mathrm{e}$ & $58,07 \mathrm{c}$ & $58,95 \mathrm{~b}$ & $52,63 \mathrm{e}$ \\
5 & $59,16 \mathrm{a}$ & $51,70 \mathrm{f}$ & $42,01 \mathrm{f}$ & $71,90 \mathrm{~b}$ \\
6 & $52,86 \mathrm{c}$ & $62,80 \mathrm{~b}$ & $49,60 \mathrm{e}$ & $54,55 \mathrm{~d}$ \\
7 & $56,53 \mathrm{~b}$ & $56,50 \mathrm{~d}$ & $56,09 \mathrm{c}$ & $74,19 \mathrm{a}$ \\
8 & $56,13 \mathrm{~b}$ & $57,14 \mathrm{~cd}$ & $64,70 \mathrm{a}$ & $37,42 \mathrm{f}$ \\
\hline
\end{tabular}

Nas colunas, as médias seguidas de pelo menos uma mesma letra comum não diferem significativamente entre si, pelo teste de Dunnet $(\mathrm{P}<0,05)$. Fonte: Dados coletados, 2015.

\section{CONCLUSÕES}

Os resultados deste trabalho revelam um alto percentual de inadequações nas temperaturas dos alimentos quentes que compõem as refeições porcionadas comercializadas no Mercado Municipal de Salinas.

Por se tratar de um assunto de saúde pública, são necessários acompanhamento e fiscalização por parte da vigilância sanitária municipal. Logo, o processo produtivo das refeições deve ser revisto e monitorado, de forma a garantir melhores temperaturas de armazenamento das preparações, garantido aos consumidores uma alimentação com menor risco higiênico-sanitário e melhor qualidade. 
ISSN: 2527-1075

\section{AGRADECIMENTOS}

Ao IFNMG - Campus Salinas pela concessão da bolsa de iniciação científica.

\section{REFERÊNCIAS}

AGÊNCIA NACIONAL DE VIGILÂNCIA SANITÁRIA. Dispõe sobre regulamento técnico de boas práticas para serviços de alimentação. Resolução RDC 216, 15 de setembro de 2004. Brasília, 2004.

BARRETO, S.M. e COSTA, M.F.L Investigação de um surto alimentar em Belo Horizonte, Brasil. Revista Cadernos de Saúde Pública, 14(2):442-443, 2006.

BRASIL. Ministério da Saúde. Agência Nacional de Vigilância Sanitária. Resolução: RDC $\mathbf{n}^{\circ} 2016$ de 15 de setembro de 2004. Dispõe sobre: Regulamento técnico de boas práticas para serviços de alimentação.

FELLOWS, P. Food Processing Technology - Principles and Practice. CRC Press LLC, Boca Raton, New York, USA, 2000.

FIELD, A. Descobrindo estatística utilizando SPSS. 2. ed. Rio de Janeiro: ArtMed, 2009.

ROCHA, B. et al. Avaliação das condições higiênico-sanitárias e da temperatura das refeições servidas em restaurantes comerciais do tipo self service. Revista do Núcleo Interdisciplinar de Pesquisa e Extensão do UNIPAM, Patos de Minas, v. 1, n. 7, v. 1, p. 30-40, ago. 2010. 